\title{
Cesarean myomectomy: Safe operation or surgical folly?
}

\author{
In many countries cesarean myomectomy is now viewed as a safe \\ and effective procedure in carefully selected clinical situations
}

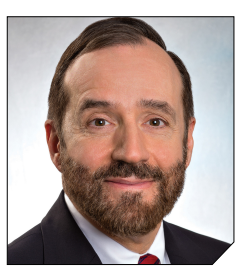

Robert L. Barbieri, MD

Chair Emeritus, Department of Obstetrics and Gynecology

Interim Chief, Obstetrics

Brigham and Women's Hospital

Kate Macy Ladd Distinguished Professor of Obstetrics,

Gynecology and Reproductive Biology

Harvard Medical School

Boston, Massachusetts
U

terine leiomyomata (fibroids) are the most common pelvic tumor of women. When women are planning to conceive, and their fibroid(s) are clinically significant, causing abnormal uterine bleeding or bulk symptoms, it is often optimal to remove the uterine tumor(s) before conception. Advances in minimally invasive surgery offer women the option of laparoscopic or robotassisted myomectomy with a low rate of operative complications, including excessive blood loss and hysterectomy, and a low rate of postoperative complications, including major pelvic adhesions and uterine rupture during subsequent pregnancy. ${ }^{1-3}$ However, many women become pregnant when they have clinically significant fibroids, and at least one-third of these women will have a cesarean birth.

Important clinical issues are the relative benefits and risks of performing a myomectomy at the time of the cesarean birth, so called cesarean myomectomy. Cesarean myomectomy offers carefully selected

doi: $10.12788 /$ obgm.0074 women the opportunity to have a cesarean birth and myomectomy in one operation, thereby avoiding a second major operation. Over the past 6 decades, most experts in the United States and the United Kingdom have strongly recommended against myomectomy at the time of cesarean delivery because of the risk of excessive blood loss and hysterectomy. Recently, expert opinion has shifted, especially in continental Europe and Asia, and cesarean myomectomy is now viewed as an acceptable surgical option in a limited number of clinical situations, including removal of pedunculated fibroids, excision of large solitary subserosal fibroids, and to achieve optimal management of the hysterotomy incision.

\section{Decades of expert guidance: Avoid cesarean myomectomy at all costs}

Dr. K.S.J. Olah succinctly captured the standard teaching that cesarean myomectomy should be avoided in this personal vignette:

Many years ago as a trainee I removed a subserosal fibroid during a cesarean section that was hanging by a thin stalk on the back of the uterus. The berating I received was severe and disproportionate to the crime. The rule was that myomectomy performed at cesarean section was not just frowned upon but expressly forbidden. It has always been considered foolish to consider removing fibroids at cesarean section, mostly because of the associated morbidity and the risk of haemorrhage requiring hysterectomy. ${ }^{4}$

Dr. Olah quoted guidance from Shaw's Textbook of Operative Gynaecology, "It should be stressed that myomectomy in pregnancy should be avoided at all costs, including at caesarean section." However, large case series published over the past 10 years report that, in limited clinical situations, cesarean myomectomy is a viable surgical option, where benefit may outweigh risk. ${ }^{6-14}$ The current literature has many weaknesses, including failure to specifically identify the indication for the cesarean myomectomy and lack of controlled prospective clinical trials. In almost 


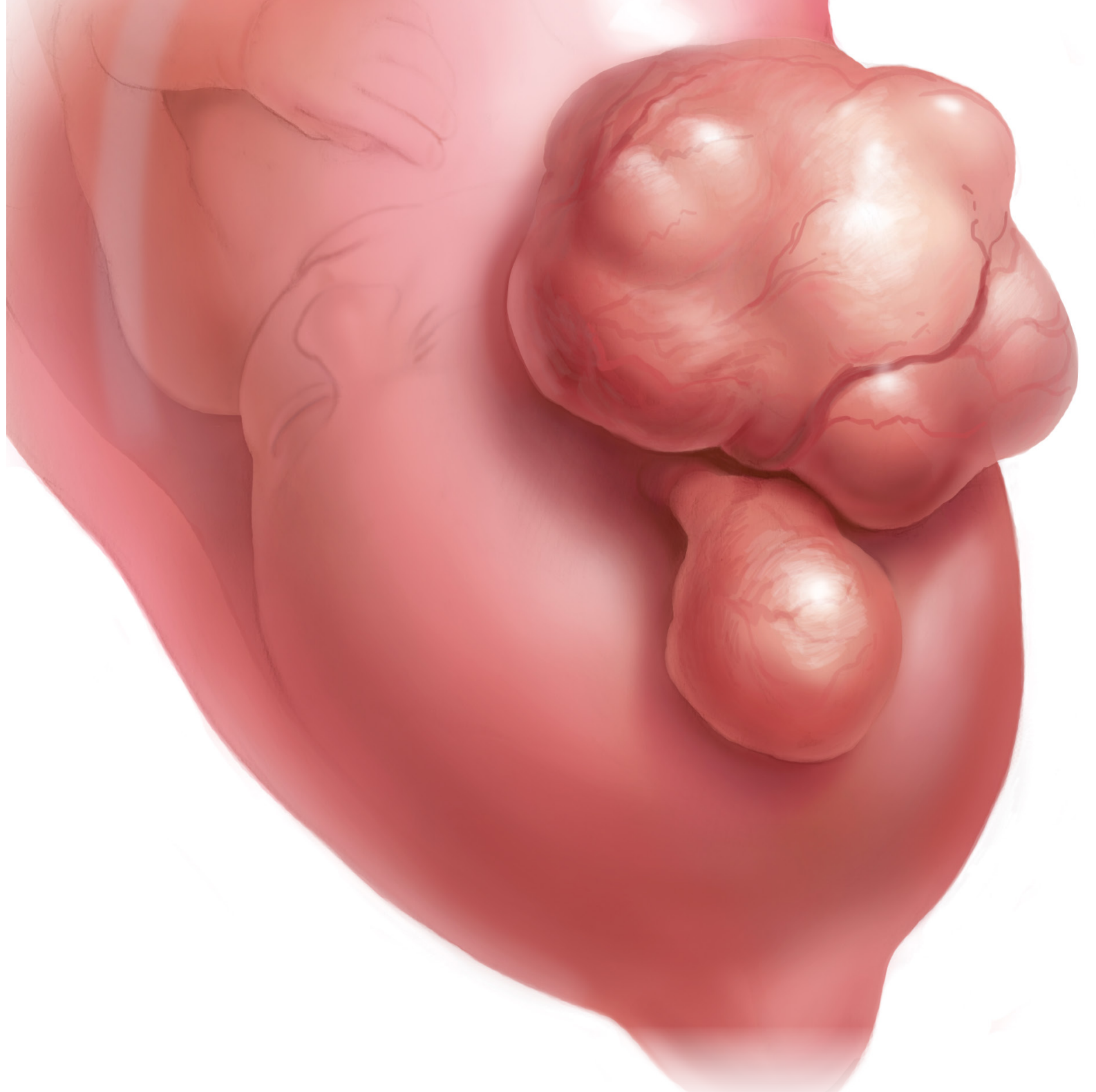

all cases, cesarean myomectomy is performed after delivery of the fetus and placenta.

\section{The pedunculated, FIGO type 7 fibroid}

The International Federation of Gynecology and Obstetrics (FIGO) leiomyoma classification system identifies subserosal pedunculated fibroids as type 7 (FIGURE, page 8). ${ }^{15}$ Pedunculated fibroids are attached to the uterus by a stalk that is $\leq 10 \%$ of the mean of the 3 diameters of the fibroid. When a clinically significant pedunculated fibroid, causing bulk symptoms, is encountered at cesarean birth, I recommend that it be removed. This will save many patients a second major operation to perform a myomectomy. The surgical risk of removing a pedunculated is low.

\section{The solitary FIGO type 6 fibroid}

Type 6 fibroids are subserosal fibroids with less than $50 \%$ of their mass being subserosal. The type 6 fibroid is relatively easy to enucleate from the uterus. Following removal of a type 6 fibroid, closure of the serosal defect is relatively straightforward. In carefully selected cases, if the type 6 fibroid is causing bulk symptoms, cesarean myomectomy may be indicated with a low risk of operative complications.

\section{The FIGO type 2-5 fibroid}

The type 2-5 fibroid is a transmural fibroid with significant mass abutting both the endometrial cavity and serosal surface. Excision of a type 2-5 fibroid is likely to result in a large transmyometrial defect that will be more difficult to close and could be associated with greater blood loss. Although data are limited, I would recommend against cesarean myomectomy for type 2-5 fibroids in most clinical situations.

\section{Myomectomy to achieve optimal management of the cesarean hysterotomy incision}

Many surgeons performing a cesarean birth for a woman with 


\section{FIGURE FIGO classification of uterine fibroids ${ }^{15}$}

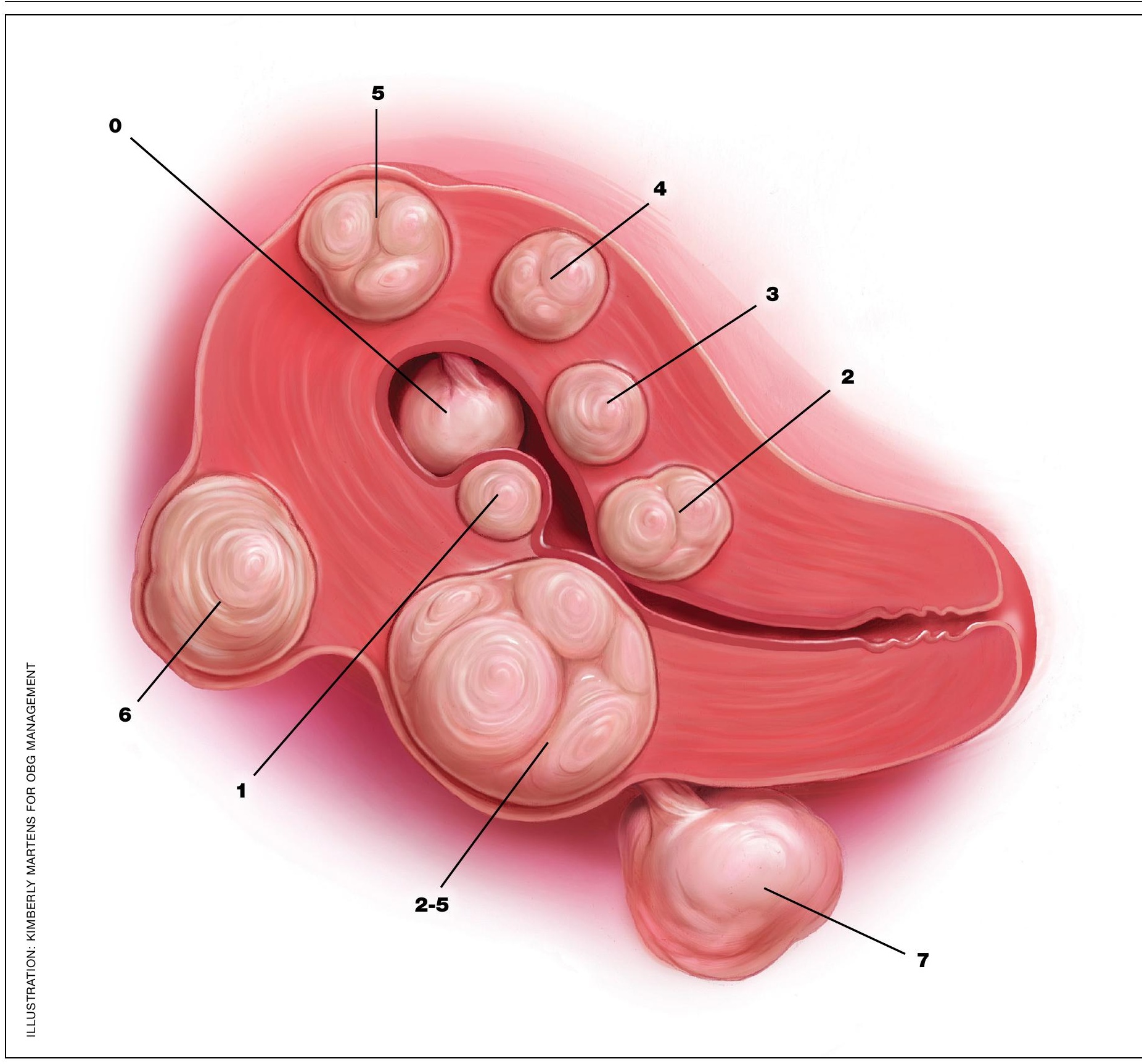

Abbreviation: FIGO, International Federation of Gynecology and Obstetrics.

clinically significant fibroids will plan the hysterotomy incision to avoid the fibroids. However, following delivery and contraction of the uterus, proper closure of the hysterotomy incision may be very difficult without removing a fibroid that is abutting the hysterotomy incision. Surgeons have reported performing myomectomy on lower uterine segment fibroids before making the hysterotomy incision in order to facilitate the hysterotomy incision and closure. ${ }^{16}$ Myomectomy prior to delivery of the newborn must be associated with additional risks to the fetus. I would prefer to identify an optimal site to perform a hysterotomy, 


\begin{tabular}{|c|c|c|}
\hline \multicolumn{2}{|l|}{ Polyp } & Coagulopathy \\
\hline \multicolumn{2}{|c|}{ Adenomyosis } & $\begin{array}{l}\text { Ovulatory } \\
\text { dysfunction }\end{array}$ \\
\hline \multicolumn{2}{|c|}{ Leiomyoma } & Endometrial \\
\hline \multicolumn{2}{|c|}{$\begin{array}{l}\text { Malignancy \& } \\
\text { hyperplasia }\end{array}$} & latrogenic \\
\hline \multirow{2}{*}{\multicolumn{2}{|c|}{$\downarrow$}} & $\begin{array}{l}\text { Not otherwise } \\
\text { classified }\end{array}$ \\
\hline & & \\
\hline \multicolumn{3}{|c|}{ Leiomyoma subclassification system } \\
\hline \multirow[t]{4}{*}{ Submucous } & 0 & $\begin{array}{l}\text { Pedunculated } \\
\text { intracavitary }\end{array}$ \\
\hline & 1 & $<50 \%$ intramural \\
\hline & 2 & $\geq 50 \%$ intramural \\
\hline & 3 & $\begin{array}{l}\text { Contacts } \\
\text { endometrium; } \\
100 \% \text { intramural }\end{array}$ \\
\hline \multirow[t]{5}{*}{ Other } & 4 & $100 \%$ Intramural \\
\hline & 5 & $\begin{array}{l}\text { Subserous and } \\
\geq 50 \% \text { intramural }\end{array}$ \\
\hline & 6 & $\begin{array}{l}\text { Subserous and } \\
<50 \% \text { intramural }\end{array}$ \\
\hline & 7 & $\begin{array}{l}\text { Subserous } \\
\text { pedunculated }\end{array}$ \\
\hline & 8 & $\begin{array}{l}\text { Other (specify eg, } \\
\text { cervical, parasitic) }\end{array}$ \\
\hline \multirow[t]{2}{*}{$\begin{array}{l}\text { Hybrid } \\
\text { (contact } \\
\text { both the } \\
\text { endometrium } \\
\text { and serosal } \\
\text { layer) }\end{array}$} & \multicolumn{2}{|c|}{$\begin{array}{l}\text { Two numbers are listed } \\
\text { separated by a hyphen. } \\
\text { By convention, the first } \\
\text { refers to the relationship } \\
\text { with the endometrium } \\
\text { while the second refers } \\
\text { to the relationship to the } \\
\text { serosa. One example is: }\end{array}$} \\
\hline & $2-5$ & $\begin{array}{l}\text { Submucous and } \\
\text { subserous, each } \\
\text { with less than half } \\
\text { the diameter in } \\
\text { the endometrial } \\
\text { and peritoneal } \\
\text { cavities, } \\
\text { respectively }\end{array}$ \\
\hline
\end{tabular}

deliver the newborn and placenta, and then consider myomectomy.

\section{Complications associated with cesarean myomectomy}

The evidence concerning the complications of cesarean birth plus myomectomy compared with cesarean birth alone in women with fibroids is limited to case series. There are no reported controlled clinical trials to guide practice. The largest single case series reported on 1,242 women with fibroids who had a cesarean birth plus myomectomy compared with 3 control groups, including 200 women without fibroids who had a cesarean birth, 145 women with fibroids who had a cesarean birth and no myomectomy, and 51 women with fibroids who had a cesarean hysterectomy. The investigators reported no significant differences in preoperative to postoperative hemoglobin change, incidence of postoperative fever, or length of hospital stay among the 4 groups. $^{8}$ The authors concluded that myomectomy during cesarean birth was a safe and effective procedure.

A systematic review and metaanalysis reported on the results of 17 studies which included 4,702 women who had a cesarean myomectomy and 1,843 women with cesarean birth without myomectomy. ${ }^{17}$ The authors of the meta-analysis noted that most reported case series had excluded women with a high risk of bleeding, including women with placenta previa, placenta accreta, coagulation disorders, and a history of multiple myomectomy operations. The investigators reported that, compared with the control women, the women undergoing cesarean myomectomy had a statistically significant but clinically insignificant decrease in mean hemoglobin concentration $(-0.27 \mathrm{~g} / \mathrm{dL})$, a significant increase in mean operative time $(+15$ minutes) and a significant increase in the length of hospital stay ( +0.36 days). There was an increase in the need for blood transfusion (risk ratio, 1.45; 95\% confidence interval, 1.05-1.99), but only $3 \%$ of women undergoing cesarean myomectomy received a blood transfusion. There was no significant difference between the two groups in the incidence of postoperative fever. The authors concluded that cesarean myomectomy is a safe procedure when performed by experienced surgeons with appropriate hemostatic techniques.

\section{Techniques to reduce blood loss at the time of cesarean myomectomy}

A detailed review of all the available techniques to reduce blood loss at the time of cesarean myomectomy is beyond the scope of this editorial. All gynecologists know that control of uterine blood flow through the uterine artery, infundibulopelvic vessels and internal iliac artery can help to reduce bleeding at the time of myomectomy. Tourniquets, vascular clamps, and artery ligation all have been reported to be useful at the time of cesarean myomectomy. In addition, intravenous infusion of oxytocin and tranexamic acid is often used at the time of cesarean myomectomy. Direct injection of uterotonics, including carbetocin, oxytocin, and vasopressin, into the uterus also has been reported. Cell saver blood salvage technology has been utilized in a limited number of cases of cesarean myomectomy. ${ }^{8,18,19}$

\section{Medicine is not a static field}

Discoveries and new data help guide advances in medical practice. After 6 decades of strict adherence to the advice that myomectomy in pregnancy should be avoided at all costs, including at caesarean delivery, new data indicate that in carefully selected cases cesarean myomectomy is an acceptable operation.

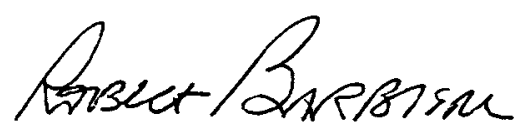

RBARBIERI@MDEDGE.COM

Dr. Barbieri reports no financial relationships relevant to this article. 


\section{EDITORIAL}

CONTINUED FROM PAGE 9

\section{References}

1. Pitter MC, Gargiulo AR, Bonaventura LM, et al. Pregnancy outcomes following robot-assisted myomectomy. Hum Reprod. 2013;28:99-108.

2. Pitter MC, Srouji SS, Gargiulo AR, et al. Fertility and symptom relief following robot-assisted laparoscopic myomectomy. Obstet Gynecol Int. 2015;2015:967568.

3. Huberlant S, Lenot J, Neron M, et al. Fertility and obstetric outcomes after robot-assisted laparoscopic myomectomy. Int J Med Robot. 2020;16:e2059.

4. Olah KSJ. Caesarean myomectomy: TE or not TE? BJOG. 2018;125:501.

5. Shaw, et al. Textbook of Operative Gynaecology. Edinburgh: Churchill Livingston; 1977.

6. Burton CA, Grimes DA, March CM. Surgical management of leiomyomata during pregnancy. Obstet Gynecol. 1989;74:707-709.

7. Ortac F, Gungor M, Sonmezer M. Myomectomy during cesarean section. Int J Gynaecol Obstet. 1999;67:189-193.

8. Li H, Du J, Jin L, et al. Myomectomy during cesarean section. Acta Obstetricia et Gynecologica.
2009;88:183-186.

9. Kwon DH, Song JE, Yoon KR, et al. Obstet Gynecol Sci. 2014;57:367-372.

10. Senturk MB, Polat M, Dogan O, et al. Outcome of cesarean myomectomy: is it a safe procedure? Geburtshilfe Frauenheilkd. 2017;77:1200-1206.

11. Chauhan AR. Cesarean myomectomy: necessity or opportunity? J Obstet Gynecol India. 2018;68:432-436.

12. Sparic R, Kadija S, Stefanovic A, et al. Cesarean myomectomy in modern obstetrics: more light and fewer shadows. J Obstet Gynaecol Res. 2017;43:798-804.

13. Ramya T, Sabnis SS, Chitra TV, et al. Cesarean myomectomy: an experience from a tertiary care teaching hospital. J Obstet Gynaecol India. 2019;69:426-430.

14. Zhao R, Wang X, Zou L, et al. Outcomes of myomectomy at the time of cesarean section among pregnant women with uterine fibroids: a retrospective cohort study. Biomed Res Int 2019;7576934.

15. Munro MG, Critchley HOD, Fraser IS; FIGO
Menstrual Disorders Committee. The two FIGO systems for normal and abnormal uterine bleeding symptoms and classification of causes of abnormal uterine bleeding in the reproductive years: 2018 revisions. In J Gynaecol Obstet. 2018;143:393.

16. Omar SZ, Sivanesaratnam V, Damodaran P. Large lower segment myoma-myomectomy at lower segment caesarean section-a report of two cases. Singapore Med J. 1999;40:109-110.

17. Goyal M, Dawood AS, Elbohoty SB, et al. Cesarean myomectomy in the last ten years; A true shift from contraindication to indication: a systematic review and meta-analysis. Eur J Obstet Gynecol Reprod Biol. 2021;256:145-157.

18. Lin JY, Lee WL, Wang $\mathrm{PH}$, et al. Uterine artery occlusion and myomectomy for treatment of pregnant women with uterine leiomyomas who are undergoing caesarean section. J Obstet Gynecol Res. 2010;36:284-290.

19. Alfred E, Joy G, Uduak O, et al. Cesarean myomectomy outcome in a Nigerian hospital district hospital. J Basic Clin Reprod Sci. 2013;2:115-118. 